\title{
Action of FPL 52694 on gastric acid secretion in the healthy human stomach
}

\author{
H-J REIMANN, U SCHMIDT, B ULTSCH, T J SULLIVAN, AND P WENDT \\ From II Medizinische Klinik and Chirurgische Klinik des Klinikums Rechts der Isar der TUM, Institute fur \\ Experimentelle Chirugie der TUM, Munich, FRG, and Science and Technology Laboratories, \\ Pharmaceutical Division, Fisons PLC, Loughborough, England
}

SUMMARY In a double blind crossover experiment in 16 healthy male volunteers, the effects of oral FPL 52694 and a matching placebo upon pentagastrin stimulated gastric acid secretion, gastric mucosal histamine content, and gastric mucosal mast cell count were compared. There was a significant increase in acid secretion, and a fall in tissue histamine and the mast cell count after treatment with the placebo. All these changes were inhibited by FPL 52694, and there was a significant difference between the effects of this compound and the placebo in all three parameters. It is concluded that FPL 52694 caused significant inhibition of acid secretion, and that the likely mechanism of action is by stabilisation of mast cells and inhibition of histamine release.

It is well recognised that histamine acts as a mediator in the body under many conditions, and that histamine release is related to gastric acid secretion. There are various ways in which the actions of histamine could be influenced; by blockade of $\mathrm{H}_{1}$ receptors or $\mathrm{H}_{2}$ receptors, ${ }^{1}$ or by inhibition of histidine decarboxylase and reduction of tissue histamine content. ${ }^{2}$ Histamine is stored in mast cells from which it can be liberated, and this can be inhibited by sodium cromoglycate which stabilises mast cells and prevents mediator release. ${ }^{3}$ FPL 52694 is a monochromone-2-carboxylic acid, an analogue of sodium cromoglycate, which also stabilises mast cells and has been shown to be an inhibitor of gastric acid secretion in humans. ${ }^{45}$ The objective of the study reported here was to obtain evidence of a direct relationship between inhibition of pentagastrin stimulated gastric acid secretion, stabilisation of gastric mucosal mast cells, and histamine secretion.

\section{Methods}

\section{SUBJECTS}

Sixteen healthy male volunteers, mean age 26.6 years (range 22-32 years) took part in the study. Each subject gave informed consent and the protocol was approved by the local hospital ethical

Address for correspondence: Dr H-J Reimann, II Medizinische Klinik des Klinikums Rechts der Isar der TUM, Munich, Federal Republic of Germany. Received for publication 10 February 1984 committee. The study was carried out according to a double blind crossover design, subjects being allocated to a treatment order group according to a randomised coding system. The two treatments used were FPL 52694 formulated in hard gelatin capsules containing $250 \mathrm{mg}$ of pure compound and matching placebo capsules containing lactose. Each treatment was taken as four capsules four times daily before food for three days, the last dose being taken four to six hours before experiment. These two treatment periods were separated by a period of 10 days.

\section{PROCEDURES}

On the first day of the study biopsies of gastric mucosa were taken from the fundus, corpus, and antrum. After a rest period of two hours, gastric acid secretion was measured using a nasogastric tube (Technicon 3000) before and during a two hour period after an intramuscular injection of pentagastrin $(6 \mu \mathrm{g} / \mathrm{kg})$. The correct position of the nasogastric tube was checked by radiography. The subject was then given the first test treatment to take for three days. On the fourth day the subject returned to the clinic and took the last treatment dose. Four to six hours later an intramuscular injection of pentagastrin was given $(6 \mu \mathrm{g} / \mathrm{kg})$, and gastric acid secretion was measured as previously described. At the end of this time mucosal biopsies were taken from the fundus, corpus, and antrum of the stomach. After a rest period of 10 days these procedures were repeated, the subject taking the 
second test treatment.

All biopsies were taken under endoscopic control (Olympus CF II). Fractions of gastric secretion were not collected regularly at 15 minute intervals as is customary. When carried out at such frequent intervals the aspiration procedure may affect gastric tissue histamine concentrations, and also the activity of metabolising enzymes. Fifteen minute samples were therefore collected for measurement of acid secretion at the following times: $15-30(-15)$ and 0-15 (0) minutes before pentagastrin administration, and at 0-15 (15), 15-30 (30), 75-90 (90) and 115-120 (120) minutes afterwards. Figures in parentheses refer to the Figure.

The tissue histamine content in biopsy specimens was estimated by using a fluorimetric method. ${ }^{6} \mathrm{~A}$ fluorescent technique based upon the use of o-phthaldialdehyde (o-pd) was used to show histamine in mast cells in the gastric mucosa. ${ }^{7}$ The treated section of the biopsy specimen was photographed. The same section was then stained with toluidine blue (tb), which non-specifically stains mast cell granules, and it was then photographed again. ${ }^{8}$ The same area (about $2-4 \mathrm{~mm}^{2}$ ) of the tissue section was taken in the two photographs. The o-pd and tb stained cells in this area were marked on a sheet of transparent paper, the cells were counted, and their number expressed as cells $/ \mathrm{mm}^{2}$ of tissue section. ${ }^{8}$

A two-tailed test has been used for statistical analysis with a significance level of $5 \%$. Statistical analyses have been carried out by comparing values obtained before and after treatment at each time point, using an analysis of variance with order group as a factor. Further analyses were carried out comparing the two treatments directly using an analysis of variance.

Standard errors (SE) of differences quoted in the

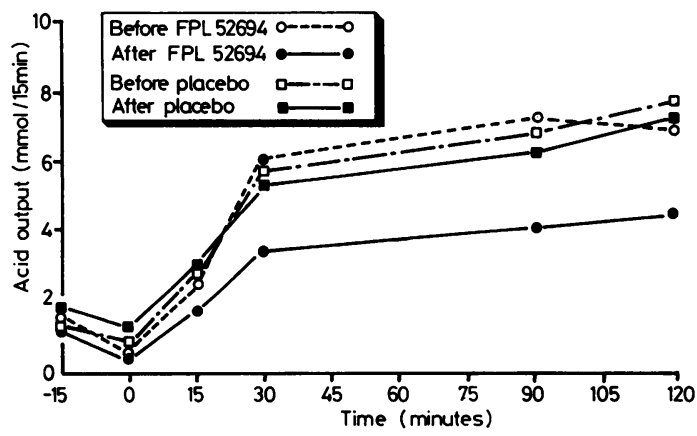

Figure Effect of FPL 52694 on pentagastrin stimulated gastric acid secretion. Means are shown at each time point. $n=16$, values $\bar{x}$ (see Table 1 for $S D$ ). tables are derived from the residual error obtained from the analysis of variance, with 14 degrees of freedom.

\section{Results}

\section{GASTRIC ACID SECRETION}

The Figure shows the mean results of four experiments carried out. It can be seen that there was little difference between the response to pentagastrin stimulation before placebo and FPL 52694 treatments, and after placebo treatment, but the secretory response after FPL 52694 treatment was considerably reduced. Table 1 shows that there were significant differences in acid secretion measured before and after treatment with FPL 52694 but none with placebo treatment.

A direct comparison of the effects of FPL 52694 and placebo on acid secretion is shown in Table 1. In the first prepentagastrin control period $(-15 \mathrm{~min})$ there was a statistically significant difference between the placebo treated and FPL 52694 treated groups, but this was not repeated in the second prepentagastrin control period $(0 \mathrm{~min})$. At every subsequent time period the gastric acid content after treatment with FPL 52694 was significantly less than after placebo.

\section{GASTRIC MUCOSAL BIOPSIES}

Biopsies were taken at the beginning of the study before pentagastrin administration, and again at the end of each treatment period, two hours after an injection of pentagastrin. Results compare the effects of treatment with placebo and FPL 52694 on tissue histamine and mast cell count in biopsy tissue.

There were highly significant differences between values for tissue histamine recorded before and after treatment with placebo, whereas after treatment with FPL 52694 no such differences were found (Table 2). A direct comparison of tissue histamine content in biopsies taken after treatment with placebo and FPL 52694 is shown in Table 2. A pentagastrin stimulated highly significant reduction in tissue histamine was recorded after placebo treatment, compared with values recorded after FPL 52694.

Table 3 shows pre- and post-treatment values for mean mast cell counts in the three areas of the stomach. When stained with o-pd there was a highly significant reduction in the mast cell count in fundus, corpus and antrum after placebo treatment. There was a very small but statistically significant reduction in the mast cell count in the fundus after treatment with FPL 52694, but no differences in samples from the corpus and antrum. After tb staining there was a significant reduction in mast cell count at all three 
Table 1 Comparison of mean values for pentagastrin stimulated gastric acid secretion (mmol/15 min) pre-and post-treatment with placebo and with FPL 52694, and comparison of the effects of these two treatments on secretion

\begin{tabular}{|c|c|c|c|c|c|c|c|c|c|}
\hline \multirow{2}{*}{$\begin{array}{l}\text { Time } \\
(\text { min })\end{array}$} & & \multicolumn{3}{|c|}{ Placebo } & \multicolumn{3}{|c|}{ FPL 52694} & \multicolumn{2}{|c|}{ Post-treatment comparison } \\
\hline & & mmol & $S E^{*}$ & $p$ & mmol & $S E^{*}$ & $p$ & $S E \dagger$ & $p$ \\
\hline \multirow[t]{2}{*}{-15} & Pre & 1.46 & & & $1 \cdot 51$ & & & & \\
\hline & Post & 1.72 & $0 \cdot 15$ & NS & 1.39 & $0 \cdot 12$ & NS & $0 \cdot 13$ & $p<0.05$ \\
\hline \multirow[t]{2}{*}{0} & Pre & $0 \cdot 80$ & & & $0 \cdot 76$ & & & & \\
\hline & Post & 0.91 & $0 \cdot 15$ & NS & $0 \cdot 71$ & $0 \cdot 14$ & NS & $0 \cdot 12$ & NS \\
\hline \multirow{2}{*}{15} & Pre & 2.77 & & & $2 \cdot 69$ & & & & \\
\hline & Post & 2.97 & $0 \cdot 17$ & NS & $1 \cdot 77$ & $0 \cdot 12$ & $\mathrm{p}<0.001$ & $0 \cdot 17$ & $\mathrm{p}<0.001$ \\
\hline \multirow[t]{2}{*}{30} & Pre & $5 \cdot 66$ & & & 5.98 & & & & \\
\hline & Post & $5 \cdot 56$ & 0.26 & NS & $3 \cdot 48$ & $0 \cdot 28$ & $\mathrm{p}<0.001$ & $0 \cdot 37$ & $\mathrm{p}<0.001$ \\
\hline \multirow[t]{2}{*}{90} & Pre & $6 \cdot 84$ & & & $7 \cdot 22$ & & & & \\
\hline & Post & $6 \cdot 39$ & 0.36 & NS & $4 \cdot 19$ & $0 \cdot 21$ & $\mathrm{p}<0.001$ & 0.33 & $\mathrm{p}<0.001$ \\
\hline \multirow[t]{2}{*}{120} & Pre & $7 \cdot 74$ & & & $7 \cdot 00$ & & & & \\
\hline & Post & $7 \cdot 31$ & 0.40 & NS & $4 \cdot 54$ & 0.38 & $\mathrm{p}<0.001$ & 0.46 & $\mathrm{p}<0.001$ \\
\hline
\end{tabular}

* SE of difference between pre- and post-treatment values.

+ SE of difference between values post-placebo and post-FPL 52694.

sites after both treatments, although the changes after placebo treatment were much greater than after FPL 52694. A direct comparison of the mast cell count at the different stomach sites after the two treatments is shown in Table 3. These confirm that there was a highly significant reduction in the mast cell count after placebo treatment compared with FPL 52694, with both methods of staining.

\section{UNUSUAL SYMPTOMS}

Sensations of repletion, mild tiredness, and sweet taste were reported by three subjects during treatment with both placebo and FPL 52694. Tiredness was reported by one subject taking placebo and another while taking active treatment. Mild headache was reported by one subject taking FPL 52694 , and loss of appetite by one subject taking placebo.

\section{Discussion}

Pentagastrin is a well known stimulant of gastric acid secretion, and it has also been shown to cause a reduction of gastric mucosal histamine in patients duodenal ulcers. ${ }^{9}$ In the experiments described above, after placebo treatment pentagastrin stimulation resulted in a significant increase in gastric acid secretion, reduction in tissue histamine concentrations and reduction in the mast cell count, as indicated by the use of both o-pd and tb staining. It has previously been shown that there is a significant correlation between changes in the results obtained by using these histochemical procedures and the histamine content of the tissues under differing experimental conditions. ${ }^{8}$ In the experiments described here, after placebo treatment the loss of histamine from cells was found to be correlated with

Table 2 Comparison of mean values for stomach mucosal tissue histamine ( $\mathrm{gg} / \mathrm{g}$ ) pre-and post-treatment with placebo and with FPL 52694, and comparison of the effects of these two treatments on tissue histamine content

\begin{tabular}{|c|c|c|c|c|c|c|c|c|c|}
\hline \multirow[b]{2}{*}{ Site } & & \multicolumn{3}{|c|}{ Placebo } & \multicolumn{3}{|c|}{ FPL 52694} & \multicolumn{2}{|c|}{ Post-treatment comparison } \\
\hline & & $\mu g / g$ & $S E^{*}$ & $p$ & $\mu g / g$ & $S E^{*}$ & $p$ & $S E \dagger$ & $p$ \\
\hline \multirow[t]{2}{*}{ Fundus } & Pre & $80 \cdot 1$ & & & $84 \cdot 1$ & & & & \\
\hline & Post & $58 \cdot 5$ & $3 \cdot 26$ & $\mathrm{p}<0.001$ & $83 \cdot 1$ & 1.49 & NS & $2 \cdot 90$ & $\mathrm{p}<0.001$ \\
\hline \multirow[t]{2}{*}{ Corpus } & Pre & $59 \cdot 8$ & & & $55 \cdot 1$ & & & & \\
\hline & Post & $41 \cdot 8$ & $1 \cdot 10$ & $\mathrm{p}<0.001$ & $56 \cdot 2$ & 1.49 & NS & 1.91 & $\mathrm{p}<0.001$ \\
\hline \multirow[t]{2}{*}{ Antrum } & Pre & $30 \cdot 7$ & & & $29 \cdot 5$ & & & & \\
\hline & Post & $20 \cdot 9$ & $0 \cdot 89$ & $\mathrm{p}<0.001$ & $30 \cdot 2$ & 0.92 & NS & 1.45 & $\mathrm{p}<0.001$ \\
\hline
\end{tabular}

* SE of difference between pre- and post-treatment values.

$\dagger$ SE of difference between values post-placebo and post-FPL 52694. 
Table 3 Comparison of mean values for mast cell count (cells per visual field) in gastric mucosal biopsies pre-and post-treatment with placebo and with FPL 52694, and comparison of the effects of these two treatments on cell counts. Cells were stained with o-phthaldialdehyde (o-pd) and toluidine blue (tb)

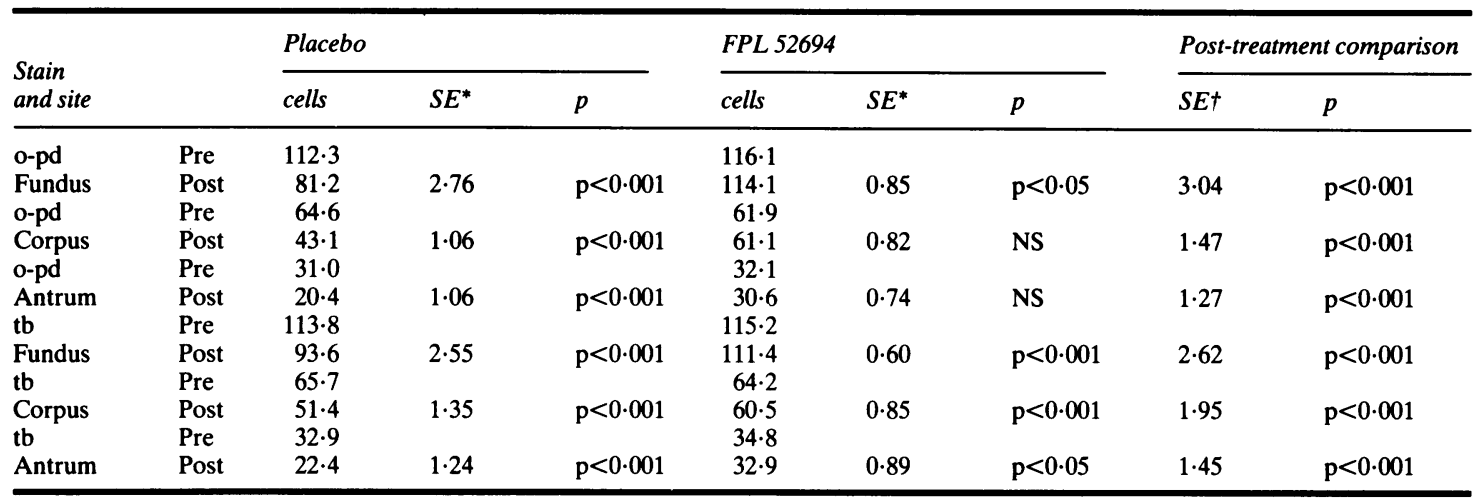

* SE of difference between pre- and post-treatment values.

+ SE of difference between values post-placebo and post-FPL 52694.

degranulation of mast cells both after o-pd staining $(\mathrm{p}<0.05)$ and after tb staining $(\mathrm{p}<0.05)$, in response to pentagastrin stimulation. Changes in the mast cell counts after o-pd and tb staining were also significantly correlated $(p<0 \cdot 001)$. It may therefore be concluded from the results recorded after placebo treatment that pentagastrin stimulation caused the release of histamine from mast cells, which could in turn have increased gastric acid secretion, and was associated with a fall in tissue histamine content. As all these effects were significantly inhibited by pretreatment with FPL 52694, it is likely that the compound acted by stabilising mast cells, and by preventing pentagastrin induced histamine release it thereby reduced the stimulus to gastric acid secretion.

Highly significant differences were shown in the mast cell counts after pentagastrin stimulation after pretreatment with placebo and FPL 52694 (Table 3). It is of interest, however, that comparison of mast cell counts pre- and post-treatment with FPL 52694 showed a significant difference after tb staining (Table 3). Although these changes were small, they were consistent throughout the subject group. A similar, very small difference was recorded in the fundus of the stomach after o-pd staining. A possible explanation of these changes is that FPL 52694 had a selective action preferentially inhibiting histamine release after non-specific degranulation of mast cells by pentagastrin.

The authors are grateful for the analysis of data carried out by Mr M T Stevens, Statistics Section, S \& T Laboratories, Pharmaceutical Division, Fisons
PLC. Supplies of FPL 52694 and matching placebo were provided by Fisons PLC.

\section{References}

1 Black JW, Duncan WAM, Durant DJ, Ganellin CR, Parsons EM. Definition and antagonism of histamine $\mathrm{H}_{2}$ receptors. Nature 1972; 236: 385.

2 Reimann H-J, Lorenz W, Fischer M, Froelich R, Meyer H-J, Schmal A. Histamine and acute haemorrhagic lesions in rat gastric mucosa: prevention of stress ulcer formation by $(+)$-catechin, an inhibitor of specific histidine decarboxylase in vitro. Agents Action 1977; 7: 69-73.

3 Cox JSG. Disodium cromoglycate. Mode of action and its possible relevance to the clinical use of the drug. $\mathrm{Br} J$ Dis Chest 1971; 65: 189-204.

4 Alban Davies H, Rhodes J, Thomas M. Inhibition of gastric acid secretion with a mast cell stabiliser, FPL 52694. Br J Clin Pharmacol 1981; 11: 53-6.

5 Nicol AK, Thomas M, Wilson J. Inhibition of gastric acid secretion by sodium cromoglycate and FPL 52694. J Pharm Pharmacol 1981; 33: 554-556.

6 Lorenz W, Reimann H-J, Barth H et al. A sensitive and specific method for the determination of histamine in human whole blood and plasma. Hoppe Seylers $Z$ Physiol Chem 1972; 353: 911-20.

7 Ehinger B, Håkanson R, Owman C, Sporrong B. Histochemical demonstration of histamine in paraffin sections by a fluorescence method. Biochem Pharmacol 1968; 17: 1997-8.

8 Mohri K, Reimann H-J, Lorenz W, Troidl H, Weber D. Histamine content and mast cells in human gastric and duodenal mucosa. Agents Actions 1978; 8: 372-5.

9 Man WK, Saunders JH, Ingoldsby C, Spencer J. Effect of pentagastrin on histamine output from the stomach in patients with duodenal ulcer. Gut 1981; 22: 916-22. 